Retraction

\title{
Retracted: Optimization, Composition, and Antioxidant Activities of Exo- and Intracellular Polysaccharides in Submerged Culture of Cordyceps gracilis (Grev.) Durieu \& Mont.
}

\author{
Evidence-Based Complementary and Alternative Medicine
}

Received 24 February 2018; Accepted 24 February 2018; Published 3 May 2018

Copyright (c) 2018 Evidence-Based Complementary and Alternative Medicine. This is an open access article distributed under the Creative Commons Attribution License, which permits unrestricted use, distribution, and reproduction in any medium, provided the original work is properly cited.

Evidence-Based Complementary and Alternative Medicine has retracted the article titled "Optimization, Composition, and Antioxidant Activities of Exo- and Intracellular Polysaccharides in Submerged Culture of Cordyceps gracilis (Grev.) Durieu \& Mont." [1] because of concerns regarding data integrity and close similarities between this article on polysaccharide yields from Cordyceps gracilis cultures and two other articles $[2,3]$ by the authors on other members of this fungal genus, Cordyceps cicadae and Cordyceps tuberculata:

(i) Sharma S. K., Gautam N., and Atri N. S., "Optimized extraction, composition, an antioxidant and antimicrobial activities of exo and intracellular polysaccharides from submerged culture of Cordyceps cicadae," BMC Complement. Altern. Med. 15: 446 (2015).

(ii) Sapan Kumar Sharma and Nandini Gautam, "Bioprospection of cordyceps tuberculata for production of bioactive polysaccharides under submerged culture conditions," EPRA International Journal of Research and Development (IJRD), 1:10, December 2016.

The methods for the Evidence-Based Complementary and Alternative Medicine and BMC Complement. Altern. Med articles are highly similar, except for the beginning. The results and discussion sections in these articles are similar and many of the same phrases were used. Because of this we asked the authors for the raw data, which the corresponding author Dr. Sharma provided. We also asked the Department of Botany at Punjabi University to provide photographs and descriptions of two herbarium specimens, PUN 6964 and PUN 7194, which they said were submitted to their herbarium by Sapan Kumar Sharma on 28.08.2014 and 10.08.2015, respectively. They provided scanned images of herbarium vouchers and specimens.

The concerns are as follows:

(1) Figure 1(b) in each article presents the same photograph, though they are meant to represent different fungal species.

(2) Tables 1 and 2 in each article show many exact digit matches between the articles for the polysaccharide yield means and standard errors, especially in Table 1 , despite the results representing different species.

(3) The distribution of insignificant digits (i.e., digits unimportant to the measured value) is expected to be uniform [4]. The decimal values in the polysaccharide yield means and standard errors in Tables 1 and 2 in the three articles have a significantly nonuniform distribution.

(4) The scanned laboratory notebooks have no dates or signatures. The raw data for the polysaccharide yield replicates do match the published means and standard errors, but this means there is a perfect match between the means and standard errors for the IPS yields by temperature between the articles in Evidence-Based Complementary and Alternative Medicine and BMC Complement. Altern. Med, even though these results correspond to different values in the underlying data. The decimal values in the raw data for the IPS yields by temperature also have a significantly nonuniform distribution.

(5) One of the Evidence-Based Complementary and Alternative Medicine article authors, Dr. Narender 
Singh Atri, said the email address used for him for the submission is not his, but he is an author of these articles in Evidence-Based Complementary and Alternative Medicine and BMC Complement. Altern. Med.

The corresponding author, Dr. Sharma, does not agree with retraction.

\section{References}

[1] S. K. Sharma, N. Gautam, and N. S. Atri, "Optimization, composition, and antioxidant activities of exo- and intracellular polysaccharides in submerged culture of Cordyceps gracilis (Grev.) Durieu \& Mont.," Evidence-Based Complementary and Alternative Medicine, vol. 2015, Article ID 462864, 8 pages, 2015.

[2] S. K. Sharma, N. Gautam, and N. S. Atri, "Optimized extraction, composition, antioxidant and antimicrobial activities of exo and intracellular polysaccharides from submerged culture of Cordyceps cicadae," BMC Complementary and Alternative Medicine, vol. 15, no. 1, article no. 446, 2015.

[3] S. K. Sharma and N. Gautam, "Bioprospection of cordyceps tuberculata for production of bioactive polysaccharides under submerged culture conditions," EPRA International Journal of Research and Development (IJRD), 2016.

[4] The Office of Research Integrity, U.S. Department of Health, Human Services, Statistical Forensics, https://ori.hhs.gov/statistical-forensics-check. 

Cordyceps gracilis (Grev.) Durieu \& Mont.

\author{
Sapan Kumar Sharma, ${ }^{1}$ Nandini Gautam, ${ }^{2}$ and Narender Singh Atri ${ }^{3}$ \\ ${ }^{1}$ Department of Plant Pathology, CSK, Himachal Pradesh Agriculture University, Palampur 176 062, India \\ ${ }^{2}$ Centre for Environment Science and Technology, School of Environmental and Earth Sciences, Central University of Punjab, \\ Bathinda 151 001, India \\ ${ }^{3}$ Department of Botany, Punjabi University, Patiala, Punjab 147 002, India
}

Correspondence should be addressed to Sapan Kumar Sharma; sapan.84.sharma@gmail.com

Received 29 November 2014; Revised 18 February 2015; Accepted 27 February 2015

Academic Editor: Zheng L. Jiang

Copyright (C) 2015 Sapan Kumar Sharma et al. This is an open access article distributed under the Creative Commons Attribution License, which permits unrestricted use, distribution, and reproduction in any medium, provided the original work is properly cited.

Under present experiments, EPS and IPS production, monosaccharide composition, and antioxidant activities of $C$. gracilis were studied for the first time under submerged culture conditions. Effect of different factors on polysaccharides production was studied by orthogonal experiments using one-factor-at-a-time method. Incubation of culture in the medium with capacity $200 \mathrm{~mL}(675.12 \pm$ 5.01 and $385.20 \pm 5.01 \mathrm{mg} / \mathrm{L})$, rotation speed $150 \mathrm{rpm}(324.62 \pm 3.32$ and $254.62 \pm 4.62 \mathrm{mg} / \mathrm{L}), 6$-day culture incubation time ( $445.24 \pm$ $1.11,216.60 \pm 1.71 \mathrm{mg} / \mathrm{L}), \mathrm{pH} 6.0(374.81 \pm 2.52$ and $219.45 \pm 2.59 \mathrm{mg} / \mathrm{L})$, and temperature $23^{\circ} \mathrm{C}(405.24 \pm 1.11 \mathrm{and} 215.60 \pm 1.71 \mathrm{mg} / \mathrm{L})$ produced higher EPS and IPS, respectively. Maximum EPS and IPS production was observed in the medium supplemented with glucose as a carbon source $(464.82 \pm 2.12$ and $264.42 \pm 2.62 \mathrm{mg} / \mathrm{L})$ and yeast extract as a nitrogen source (465.21 \pm 3.11 and $245.17 \pm$ $3.24 \mathrm{mg} / \mathrm{L})$, respectively. Carbon to nitrogen ratio for maximum EPS and IPS production was observed as $10: 1$ (395.29 \pm 2.15 and $235.62 \pm 1.40 \mathrm{mg} / \mathrm{L})$, respectively. Glucose was found to be the major monosaccharide $(62.15 \pm 7.33 \%)$. Both EPS and IPS of C. gracilis showed significant DPPH radical scavenging activity, ABTS radical scavenging activity, reducing power, and iron chelating activity.

\section{Introduction}

Cordyceps Fr. is a widespread genus with 400 species worldwide [1-3]. Many species of this genus have been reported as the source of disease combating natural products with tremendous biological activities and considered as a rare and exotic medicinal fungus for centuries. Fruit bodies and mycelial extracts of this fungus have been found to exhibit different pharmacological activities [4]. Cordyceps sinensis (Berk.) Sacc. has been used extensively to cure various cancerous diseases and known to have different immunomodulatory activities [5-10]. Polysaccharides present in Cordyceps mycelium constitute the main bioactive agents and their range in Cordyceps species varies within
$3-8 \%$ of the total weight [11-13]. Recent studies on the composition of anamorphic Cordyceps species have revealed higher percentage of cordycepin and other biological active compounds [14]. Previous studies have shown that Cordyceps species possesses liver protective effects [15], antioxidative activities [16], enhances the T-cell and macrophages activity [17], reduce the level of c-Myc, c-Fos, and VEGF levels in the lungs and liver by exopolysaccharide fraction [18], and reduce the level of cholesterol and triglyceride [19]. Besides these, Cordyceps contains some uncommon cyclic dipeptides, including cyclo-[Gly-Pro], cyclo-[Leu-Pro], cyclo-[Val-Pro], cyclo-[Ala-Leu], cyclo-[Ala-Val], and cyclo-[Thr-Leu] and small amounts of polyamines, such as 1,3-diamino propane, cadaverine, spermidine, spermine, and putrescine [20]. 
Polysaccharides extracted from Cordyceps species were known to exhibit multiple pharmacological activities including antitumor, anti-inflammatory, immunopotentiation, hypoglycemic, and hypocholesterolemic effects, protection of neuronal cells against the free radical-induced cellular toxicity, steroidogenesis, and antioxidant activities [21-27]. Polysaccharides isolated from the mycelia of Cordyceps fungi have been known to possess antioxidant properties which provide health benefits in preventing damage due to free radicals produced by biological degeneration [28-32].

Commercial cultivation through submerged culture is now becoming quite useful because of higher mycelial yield with fewer chances of contamination [33, 34]. EPS as well as IPS extracted from submerged culture possess the same biological activities [35]. However, the productivity of polysaccharides has been found to vary with environmental conditions and medium composition, including carbon source, nitrogen source, and $\mathrm{pH}$ [36]. In view of this, present studies were conducted to optimize the EPS and IPS production by one-factor-at-a-time method and orthogonal matrix method, monosaccharide composition and to evaluate the antioxidant activities of EPS and IPS in submerged culture of C. gracilis.

\section{Materials and Methods}

2.1. Culturing and Optimization Studies on Polysaccharides Production. Cordyceps gracilis was collected from Northwest India and was deposited at Herbarium, Department of Botany, Punjabi University, Patiala (PUN 6964). Isolation was done on potato dextrose agar (PDA) slants. The slants were incubated at $25^{\circ} \mathrm{C}$ for 10 days. Subculturing was done in every 45 -day interval to maintain them viable. Submerged culturing was done in a standard basal medium (saccharine $30.0 \mathrm{~g} / \mathrm{L}$, yeast powder $5.0 \mathrm{~g} / \mathrm{L}$, peptone $5.0 \mathrm{~g} / \mathrm{L}, \mathrm{MgSO}_{4} \cdot 7 \mathrm{H}_{2} \mathrm{O}$ $1.0 \mathrm{~g} / \mathrm{L}$, and $\mathrm{KH}_{2} \mathrm{PO}_{4} 0.5 \mathrm{~g} / \mathrm{L}$ ) [37, 38]. Effect of medium capacity $(50,100,150,200$, and $250 \mathrm{~mL})$, rotation speed $(50,100,125,150,175$, and $200 \mathrm{rpm})$ of culture medium, incubation time (2-10 days), $\mathrm{pH}(3.0-8.0)$, temperature (20, $23,25,27,30$, and $33^{\circ} \mathrm{C}$ ), carbon sources (glucose, galactose, sucrose, mannitol, maltose, and fructose), nitrogen sources (yeast extract, peptone, $\mathrm{NaNO}_{2}\left(\mathrm{NH}_{4}\right)_{2} \mathrm{SO}_{4}$, and L-arginine $\mathrm{HCL})$, and $\mathrm{C} / \mathrm{N}(1: 5,1: 10,1: 20,1: 30$, and $1: 40)$ ratio on EPS and IPS production was studied by orthogonal experiments using one-factor-at-a-time method.

2.2. Extraction of EPS and IPS. Exopolysaccharides (EPS) were extracted by the standard method with minor modifications [39]. Briefly, mycelial biomass in the medium was centrifuged at $10,000 \times \mathrm{g}$ for $12 \mathrm{~min}$. The supernatant obtained was mixed with three volumes of pure ethanol and left for 24 hours at $4^{\circ} \mathrm{C}$. The resulting precipitate was then separated by centrifugation at $8000 \times \mathrm{g}$ for $10 \mathrm{~min}$. The precipitate (EPS) was washed with ultrapure water and subsequently lyophilized for quantitative assessment and analysis.

For intracellular polysaccharides, mycelial biomass was subjected to extraction with boiling water for an hour and the mixture was filtered through Whatman number 1 filter paper. The filtrate was allowed to precipitate with four volumes of
95\% (v/v) ethanol and left overnight at $4^{\circ} \mathrm{C}$. The polysaccharides thus precipitated were separated by centrifugation at $8000 \times \mathrm{g}$ for $10 \mathrm{~min}$. The precipitates (IPS) were washed with ultrapure water and subsequently lyophilized for quantitative assessment and analysis [40].

2.3. Polysaccharides Composition. Monosaccharide composition of polysaccharides was determined by high performance liquid chromatography coupled to an evaporative light scattering detector [41]. Polysaccharide fraction $(0.1 \mathrm{~g})$ was extracted with $2.5 \mathrm{~mL}$ of $70 \%$ aqueous methanol followed by $1.5 \mathrm{~mL}$ of $70 \%$ aqueous methanol and then $1 \mathrm{~mL}$ of $70 \%$ aqueous methanol. This extract was centrifuged at $4000 \mathrm{rpm}$ at $4^{\circ} \mathrm{C}$ for $10 \mathrm{~min}$. Supernatant was collected and volume made up to $5 \mathrm{~mL}$ with $70 \%$ methanol. The extract was passed through Millipore filter $(0.45 \mu \mathrm{m})$ prior to injection on the HPLC.

2.4. DPPH Radical Scavenging Activity. The DPPH scavenging activity was measured by the standard method described by Vamanu [42]. Briefly, DPPH $(200 \mu \mathrm{m})$ solution at different concentrations $(2-10 \mathrm{mg} / \mathrm{mL})$ was added to $0.05 \mathrm{~mL}$ of the samples dissolved in ethanol. An equal amount of ethanol was added to the control. Ascorbic acid was used as the control. The absorbance was read after $20 \mathrm{~min}$ at $517 \mathrm{~nm}$ and the inhibition was calculated using the formula

$$
\text { DPPH scavenging effect }(\%)=A_{0}-\frac{A_{P}}{A_{0} \times 100},
$$

where $A_{0}$ was the absorbance of the control and $A_{P}$ was the absorbance in the presence of the sample.

EC50 values were calculated using different sample concentrations $(2-10 \mathrm{mg} / \mathrm{mL})$ to obtain antiradical curves. Antiradical curves were plotted referring to concentration on the $x$-axis and relative scavenging capacity on the $y$-axis. EC50 values were calculated using the following equation:

$$
\mathrm{EC} 50=10^{\log x 0},
$$

where ${ }^{\log x 0}$ is the center of the curve.

2.5. ABTS Radical Scavenging Assay. ABTS radical scavenging activity was measured by the method described by Li et al. [43]. For this, $10 \mu \mathrm{L}$ of the sample was added to $4 \mathrm{~mL}$ of the diluted $\mathrm{ABTS}^{*+}$ solution (prepared by adding $7 \mathrm{mM}$ of the ABTS stock solution to $2.45 \mathrm{mM}$ potassium persulfate, kept in the dark, at room temperature, for 12-16 h before use). The solution was then diluted with $5 \mathrm{mM}$ phosphate-buffered saline (pH 7.4) to an absorbance at $730 \mathrm{~nm}$ of $0.70 \pm 0.02$ [43]. After the addition of $10 \mu \mathrm{L}$ of the sample to $4 \mathrm{~mL}$ of the diluted $\mathrm{ABTS}^{*+}$ solution, the absorbance was measured at $30 \mathrm{~min}$. Ascorbic acid was used as control. The ABTS radical scavenging activity was calculated as

$$
S \%=\left(A_{\text {control }}-\frac{A_{\text {sample }}}{A_{\text {control }}}\right) \times 100 .
$$

Different sample concentrations $(2-10 \mathrm{mg} / \mathrm{mL})$ were used to obtain EC50 values. Standard curve was prepared with 
the sample concentration on the $x$-axis and relative scavenging capacity on the $y$-axis. EC50 values were calculated using the following equation:

$$
\mathrm{EC} 50=10^{\log x 0},
$$

where ${ }^{\log x 0}$ is the center of the curve.

2.6. Reducing Power. Reducing power was estimated by the standard method given by Papuc et al. [44]. Briefly, $200 \mu \mathrm{L}$ of the samples was mixed with sodium phosphate buffer ( $\mathrm{pH}$ 6.6), $1 \mathrm{mM} \mathrm{FeSO}_{4}$, and $1 \%$ potassium ferricyanide and incubated for $20 \mathrm{~min}$ at $50^{\circ} \mathrm{C}$; after that trichloroacetic acid was added and the mixtures were centrifuged. Supernatant $(2.5 \mathrm{~mL})$ was mixed with an equal volume of water and $0.5 \mathrm{~mL} 0.1 \% \mathrm{FeCl}_{3}$. The absorbance was measured at $700 \mathrm{~nm}$. Reducing power of the samples was calculated using EC50 values with different sample concentrations $(2-10 \mathrm{mg} / \mathrm{mL})$. Standard curve was made referring to concentration on the $x$-axis and relative scavenging capacity on the $y$-axis. EC50 values were calculated using the following equation:

$$
\mathrm{EC} 50=10^{\log x 0},
$$

where ${ }^{\log x 0}$ is the center of the curve.

2.7. Ferrous Ion Chelating Assay. For this, $1 \mathrm{~mL}$ of the sample $(2-10 \mathrm{mg} / \mathrm{mL})$ was mixed with $3.7 \mathrm{~mL}$ of ultrapure water, following which the mixture was reacted with ferrous chloride $(2 \mathrm{mmol} / \mathrm{L}, 0.1 \mathrm{~mL})$ and ferrozine $(5 \mathrm{mmol} / \mathrm{L}, 0.2 \mathrm{~mL})$ for $20 \mathrm{~min}$. And the absorbance was read at $562 \mathrm{~nm}$. EDTA was used as positive control. The chelating activity on the ferrous ion was calculated using the following formula: chelating activity $(\%)=\left[\left(A_{b}-A_{s}\right) / A_{b}\right] \times 100$, where $A_{b}$ is the absorbance of the blank and $A_{s}$ is the absorbance in the presence of the extract [45]. Chelating activity of samples was calculated using EC50 values with different sample concentrations $(2-10 \mathrm{mg} / \mathrm{mL})$ by standard curve referring to concentration on the $x$-axis and chelating activity on the $y$-axis. EC50 values were calculated using the following equation:

$$
\mathrm{EC} 50=10^{\log x 0},
$$

where ${ }^{\log x 0}$ is the center of the curve.

2.8. ExperimentalDesign. Different factors considered for the orthogonal design were carbon sources, nitrogen sources, and ratio of carbon to nitrogen sources, temperature, $\mathrm{pH}$ value, medium capacities, rotation speed, and culture time. According to the results of the single factor experiment, the orthogonal $\mathrm{L}_{9}\left(3^{4}\right)$ was used for optimal culture conditions in submerged cultures.

2.9. Statistical Methods. All results are expressed as mean \pm standard error. $P<0.05$ was considered significant, and SPSS software (SPSS Inc., Chicago, IL, USA) was used to calculate differences. All experiments were performed at least
3 times and with 3 replicates. The results were analyzed using one-way analysis of variance (ANOVA). Tests of significant differences were determined by Tukey-HSD at $P<0.05$.

\section{Results and Discussion}

3.1. Optimization of Submerged Culture Conditions and Polysaccharide Composition. To find the suitable medium capacity for maximum EPS and IPS production, Cordyceps gracilis was grown in flasks $(500 \mathrm{~mL})$ containing liquid media with different capacities. The maximum EPS (675.12 \pm $4.01 \mathrm{mg} / \mathrm{L})$ and IPS $(385.20 \pm 3.00 \mathrm{mg} / \mathrm{L})$ production was observed in $200 \mathrm{~mL}$ of the medium, while the least values for EPS $(302.17 \pm 4.46 \mathrm{mg} / \mathrm{L})$ and IPS $(122.13 \pm 5.46 \mathrm{mg} / \mathrm{L})$ production were obtained in $50 \mathrm{~mL}$ of the medium. However, no significant difference $P<0.05$ was observed in EPS and IPS production in the medium with $100-150 \mathrm{~mL}$ capacities. Variation in rotation speed showed a direct relation with EPS and IPS production. Results obtained for the effect of the rotation speed on polysaccharide production showed maximum EPS $(324.62 \pm 3.32 \mathrm{mg} / \mathrm{L})$ and IPS $(254.62 \pm 4.62 \mathrm{mg} / \mathrm{L})$ production in culture medium with rotation speed $150 \mathrm{rpm}$. Similar results were obtained for medicinal fungus $C$. ophioglossoides (Ehrh.) Link and other ascomycetes. The reason for this is low oxygen requirement by the culture at $150 \mathrm{rpm}$ rotation [27, 37]. The results obtained under present experiments on the effect of rotation speed on polysaccharide production were the same as those obtained in C. ophioglossoides [37]. Culture incubation time and $\mathrm{pH}$ range showed significant effect on EPS and IPS production. C. gracilis incubated for 6 days and pH 6.0 showed maximum EPS and IPS production (Table 1). In the species, namely, C. ophioglossoides and C. sinensis, incubation period of 5-6 days and slightly acidic $\mathrm{pH} 5.0-$ 6.0 promoted maximum IPS production $[37,46]$. C. gracilis culture showed maximum EPS $(405.24 \pm 1.11 \mathrm{mg} / \mathrm{L})$ and IPS $(215.60 \pm 1.71 \mathrm{mg} / \mathrm{L})$ production at $23^{\circ} \mathrm{C}$. This temperature for C. sinensis was observed as $20^{\circ} \mathrm{C}$ and, for C. ophioglossoides, it was found to be $25^{\circ} \mathrm{C}[37,47]$.

Six different carbon sources were studied to find the suitable medium source for the production of EPS and IPS in Cordyceps gracilis. Although all the tested carbon sources yielded EPS and IPS, maximum EPS $(464.82 \pm 2.12 \mathrm{mg} / \mathrm{L})$ and IPS $(264.42 \pm 2.62 \mathrm{mg} / \mathrm{L})$ production took place in the medium supplemented with glucose as carbon source. Glucose was also found to be the most favorable carbon source for polysaccharide production in many of the Cordyceps species $[37,48,49]$. To find the best nitrogen source, six different nitrogen sources were selected. Amongst them, yeast extract provided maximum EPS $(465.21 \pm 3.11 \mathrm{mg} / \mathrm{L})$ and IPS (245.17 $\pm 3.24 \mathrm{mg} / \mathrm{L}$ ) production. The results obtained under present studies are similar to those obtained from other researches [47]. C/N ratio $10: 1$ promoted maximum EPS (395.29 \pm $2.15 \mathrm{mg} / \mathrm{L})$ and IPS $(235.62 \pm 1.40 \mathrm{mg} / \mathrm{L})$ production for $C$. gracilis (Table 2). Present results are in conformity with previous reports on C. ophioglossoides, as $\mathrm{C} / \mathrm{N}$ ratio $10: 1$ provided maximum IPS (653.79 $\pm 5.24 \mathrm{mg} / \mathrm{L})$ production [37].

Monosaccharide composition of polysaccharides showed glucose in major percentage $(62.15 \pm 7.33 \%)$ followed by 
TABLE 1: Effect of different factors on EPS and IPS yield in submerged culture of C. gracilis.

\begin{tabular}{|c|c|c|}
\hline Sources & EPS (mg/L) & IPS (mg/L) \\
\hline \multicolumn{3}{|c|}{ Medium capacity/mL } \\
\hline 50 & $302.17 \pm 4.46^{\mathrm{a}}$ & $122.13 \pm 5.46^{\mathrm{a}}$ \\
\hline 100 & $450.10 \pm 5.46^{\mathrm{a}}$ & $203.13 \pm 4.48^{\mathrm{a}}$ \\
\hline 150 & $449.12 \pm 4.62^{\mathrm{a}}$ & $204.62 \pm 4.62^{\mathrm{a}}$ \\
\hline 200 & $675.12 \pm 4.01^{\mathrm{b}}$ & $385.20 \pm 3.00^{\mathrm{b}}$ \\
\hline 250 & $403.11 \pm 5.46^{\mathrm{a}}$ & $199.13 \pm 5.46^{\mathrm{a}}$ \\
\hline \multicolumn{3}{|c|}{ Rotation speed (rpm) } \\
\hline 50 & $213.17 \pm 2.46^{\mathrm{a}}$ & $121.12 \pm 1.62^{\mathrm{a}}$ \\
\hline 100 & $244.62 \pm 2.12^{\mathrm{a}}$ & $152.13 \pm 5.46^{\mathrm{a}}$ \\
\hline 125 & $255.20 \pm 2.51^{\mathrm{a}}$ & $185.20 \pm 5.01^{\mathrm{a}}$ \\
\hline 150 & $324.62 \pm 3.32^{\mathrm{b}}$ & $254.62 \pm 4.62^{\mathrm{b}}$ \\
\hline 175 & $283.13 \pm 2.49^{\mathrm{a}}$ & $198.13 \pm 5.46^{\mathrm{a}}$ \\
\hline 200 & $187.20 \pm 2.01^{\mathrm{a}}$ & $125.20 \pm 5.01^{\mathrm{a}}$ \\
\hline \multicolumn{3}{|c|}{ Incubation time/d } \\
\hline 2 & $253.10 \pm 3.16^{\mathrm{a}}$ & $123.12 \pm 3.42^{\mathrm{a}}$ \\
\hline 3 & $265.22 \pm 2.21^{\mathrm{a}}$ & $145.17 \pm 3.01^{\mathrm{abc}}$ \\
\hline 4 & $314.12 \pm 1.32^{\mathrm{a}}$ & $164.69 \pm 2.02^{\mathrm{ab}}$ \\
\hline 5 & $353.19 \pm 4.16^{\mathrm{ad}}$ & $173.63 \pm 2.46^{\mathrm{b}}$ \\
\hline 6 & $445.24 \pm 1.11^{\mathrm{ab}}$ & $216.60 \pm 1.71^{b c}$ \\
\hline 7 & $304.82 \pm 2.12^{\mathrm{a}}$ & $164.42 \pm 2.62^{\mathrm{ab}}$ \\
\hline 8 & $253.71 \pm 1.43^{\mathrm{a}}$ & $157.49 \pm 1.46^{\mathrm{abc}}$ \\
\hline 9 & $245.24 \pm 4.11^{\mathrm{ac}}$ & $149.22 \pm 1.91^{\mathrm{abc}}$ \\
\hline 10 & $204.52 \pm 1.63^{\mathrm{acd}}$ & $134.02 \pm 2.12^{\mathrm{abc}}$ \\
\hline \multicolumn{3}{|l|}{$\mathrm{pH}$} \\
\hline 3.0 & $324.11 \pm 1.15^{\mathrm{a}}$ & $154.60 \pm 2.12^{\mathrm{a}}$ \\
\hline 4.0 & $343.14 \pm 1.19^{\mathrm{a}}$ & $173.61 \pm 2.16^{\mathrm{ab}}$ \\
\hline 5.0 & $355.29 \pm 2.15^{\mathrm{a}}$ & $185.62 \pm 1.49^{\mathrm{ab}}$ \\
\hline 6.0 & $374.81 \pm 2.52^{\mathrm{ab}}$ & $219.45 \pm 2.59^{\mathrm{b}}$ \\
\hline 7.0 & $353.79 \pm 2.44^{\mathrm{a}}$ & $197.59 \pm 5.16^{\mathrm{ab}}$ \\
\hline 8.0 & $247.19 \pm 2.11^{\mathrm{ac}}$ & $169.12 \pm 4.93^{\mathrm{ab}}$ \\
\hline \multicolumn{3}{|c|}{ Temperature } \\
\hline 20 & $362.19 \pm 2.16^{\mathrm{a}}$ & $172.63 \pm 2.33^{\mathrm{a}}$ \\
\hline 22 & $405.24 \pm 1.11^{\mathrm{b}}$ & $215.60 \pm 1.71^{\mathrm{ab}}$ \\
\hline 25 & $394.82 \pm 2.55^{\mathrm{c}}$ & $162.42 \pm 2.62^{\mathrm{a}}$ \\
\hline 27 & $253.71 \pm 1.46^{\mathrm{d}}$ & $159.49 \pm 1.46^{\mathrm{a}}$ \\
\hline 30 & $209.24 \pm 4.91^{\mathrm{e}}$ & $147.22 \pm 1.91^{\mathrm{a}}$ \\
\hline 35 & $103.19 \pm 4.10^{\mathrm{f}}$ & $63.10 \pm 2.46^{\mathrm{ac}}$ \\
\hline
\end{tabular}

Values are expressed as mean \pm SE and the same alphabets in the same column are not statistically significant according to Tukey's test for multiple comparisons with $P<0.05$ for different conditions as mentioned in the table.

rhamnose $(36.81 \pm 4.57 \%)$ and galactose in minor quantities $(0.10 \pm 0.0 \%)$ (Table 3$)$. Similar results were obtained for polysaccharide composition of C. militaris (L.) Link and other medicinal basidiomycetes, in which glucose was found to be the major monosaccharide along with sucrose and galactose $[42,50]$.

Results obtained for influence of different factors on yield of EPS and IPS showed a significant positive effect. Results revealed the effect on EPS and IPS production in the order
TABLE 2: Effect of different factors on EPS and IPS yield in submerged culture of $C$. gracilis.

\begin{tabular}{|c|c|c|}
\hline Factors & EPS $(\mathrm{mg} / \mathrm{L})$ & IPS (mg/L) \\
\hline \multicolumn{3}{|l|}{ Carbon sources } \\
\hline Mannitol & $319.12 \pm 1.82^{\mathrm{a}}$ & $164.69 \pm 2.02^{\mathrm{a}}$ \\
\hline Galactose & $353.19 \pm 3.19^{\mathrm{a}}$ & $173.63 \pm 2.46^{\mathrm{a}}$ \\
\hline Sucrose & $305.24 \pm 1.11^{\mathrm{a}}$ & $216.60 \pm 1.71^{\mathrm{a}}$ \\
\hline Glucose & $464.82 \pm 2.12^{\mathrm{ab}}$ & $264.42 \pm 2.62^{\mathrm{ab}}$ \\
\hline Maltose & $253.71 \pm 1.43^{\mathrm{a}}$ & $157.49 \pm 1.46^{\mathrm{a}}$ \\
\hline Fructose & $245.24 \pm 4.11^{\mathrm{ac}}$ & $149.22 \pm 1.91^{\mathrm{ac}}$ \\
\hline \multicolumn{3}{|l|}{ Nitrogen source } \\
\hline Yeast extract & $465.21 \pm 3.11^{\mathrm{a}}$ & $245.17 \pm 3.24^{\mathrm{a}}$ \\
\hline Peptone & $324.12 \pm 1.32^{\mathrm{a}}$ & $164.69 \pm 2.69^{\mathrm{a}}$ \\
\hline $\mathrm{NaNO}_{2}$ & $345.24 \pm 2.17^{\mathrm{a}}$ & $146.60 \pm 1.71^{\mathrm{a}}$ \\
\hline$\left(\mathrm{NH}_{4}\right)_{2} \mathrm{SO}_{4}$ & $304.82 \pm 2.12^{\mathrm{a}}$ & $104.42 \pm 2.62^{\mathrm{a}}$ \\
\hline $\mathrm{L}$-arginine $\mathrm{HCL}$ & $263.71 \pm 3.43^{\mathrm{a}}$ & $107.49 \pm 3.46^{\mathrm{a}}$ \\
\hline DL-ascorbic acid & $255.24 \pm 4.11^{\mathrm{b}}$ & $99.22 \pm 1.91^{\mathrm{b}}$ \\
\hline \multicolumn{3}{|l|}{$\mathrm{C} / \mathrm{N}$ ratio } \\
\hline $40: 1$ & $117.70 \pm 1.07^{\mathrm{a}}$ & $97.79 \pm 1.59^{\mathrm{a}}$ \\
\hline $30: 1$ & $324.11 \pm 1.71^{\mathrm{a}}$ & $154.60 \pm 2.32^{\mathrm{a}}$ \\
\hline $20: 1$ & $343.14 \pm 1.19^{\mathrm{a}}$ & $173.61 \pm 2.16^{\mathrm{a}}$ \\
\hline $10: 1$ & $395.29 \pm 2.15^{\mathrm{b}}$ & $235.62 \pm 1.40^{\mathrm{b}}$ \\
\hline $5: 1$ & $374.81 \pm 2.52^{\mathrm{a}}$ & $219.45 \pm 2.59^{\mathrm{a}}$ \\
\hline $1: 1$ & $353.79 \pm 2.44^{\mathrm{a}}$ & $197.59 \pm 5.16^{\mathrm{a}}$ \\
\hline \multirow{2}{*}{\multicolumn{3}{|c|}{$\begin{array}{l}\text { Values are expressed as mean } \pm \text { SE and the same alphabets in the same } \\
\text { column are not statistically significant according to Tukey's test for multiple } \\
\text { comparisons with } P<0.05 \text { for different conditions as mentioned in the table. } \\
\text { TABLE 3: Monosaccharide composition (mean } \pm \text { SE) of polysaccha- } \\
\text { rides in C. gracilis. }\end{array}$}} \\
\hline & & \\
\hline Monosaccharides & & $(\%)$ \\
\hline Xylose & & $21.14 \pm 5.19$ \\
\hline Glucose & & $62.15 \pm 7.33$ \\
\hline Rhamnose & & $36.81 \pm 4.57$ \\
\hline Mannose & & $13.76 \pm 2.44$ \\
\hline Galactose & & $0.10 \pm 0.0$ \\
\hline
\end{tabular}

temperature $>$ incubation time $>\mathrm{pH}>$ rotation speed $>$ medium capacity (Table 4$)$.

3.2. Antioxidant Activities of EPS and IPS. The DPPH free radical scavenging activity of EPS and IPS extracted from the mycelium of C. gracilis showed positive and direct correlation with the concentration of the sample (Figure 1(c)). Both EPS and IPS extracted from C. gracilis showed high DPPH scavenging activity. However, EPS showed higher DPPH scavenging activity than IPS. The results are supported by $\mathrm{EC}_{50}$ values, which were found to be $7.32 \pm 0.09 \mathrm{mg} / \mathrm{mL}$ for EPS and $6.79 \pm 0.04 \mathrm{mg} / \mathrm{mL}$ for IPS (Table 5 ). These results are in conformity with previous reports on other medicinally important species like C. militaris and C. sinensis [51, 52]. The inhibition percentage of the ABTS radical by EPS and IPS of C. gracilis was found to be directly dependent upon the concentration of the sample. The scavenging effect of all 


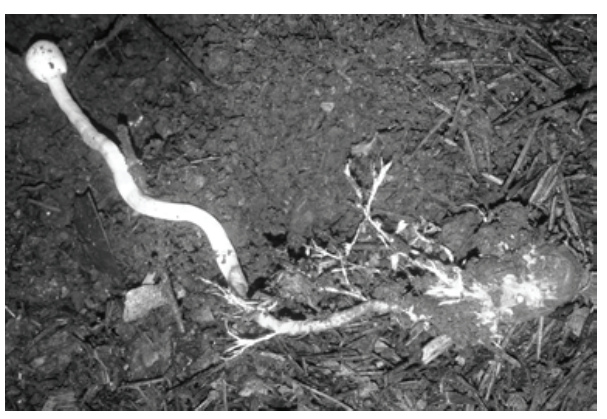

(a)

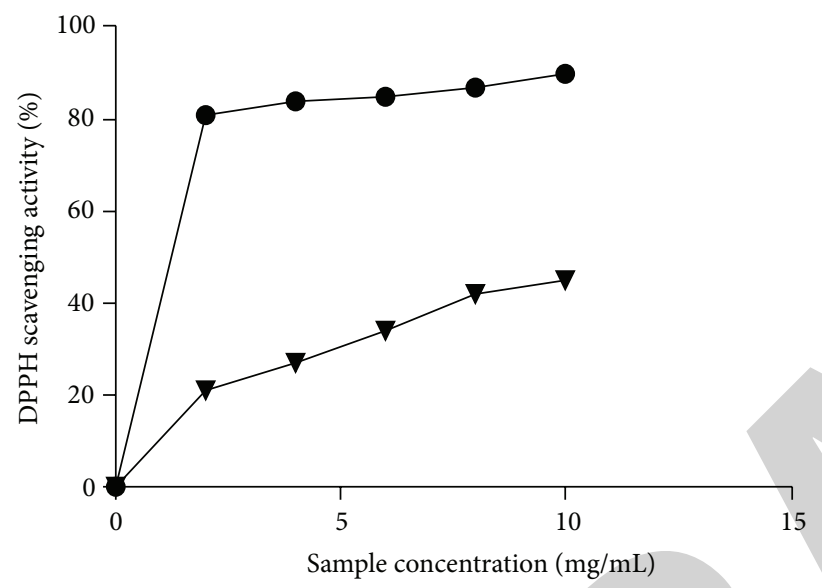

(c)

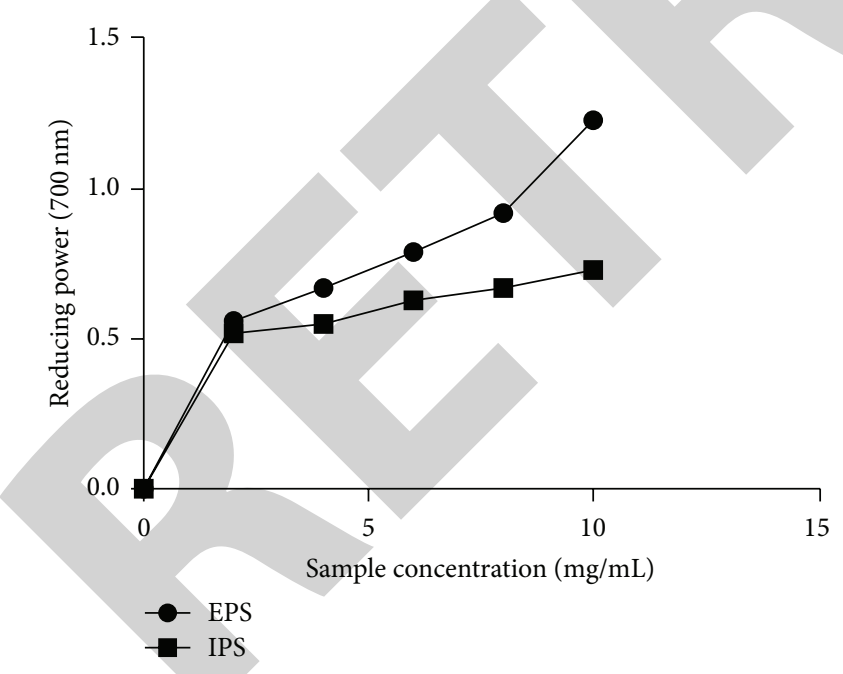

(e)

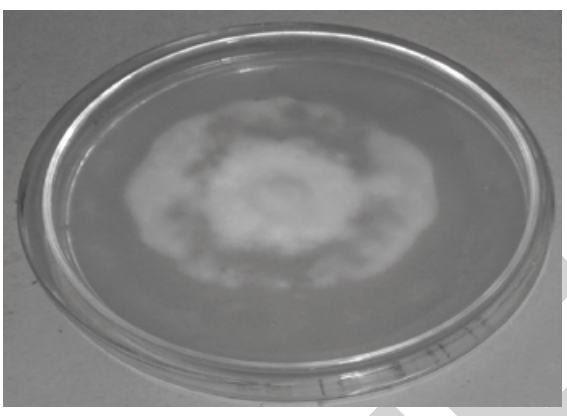

(b)

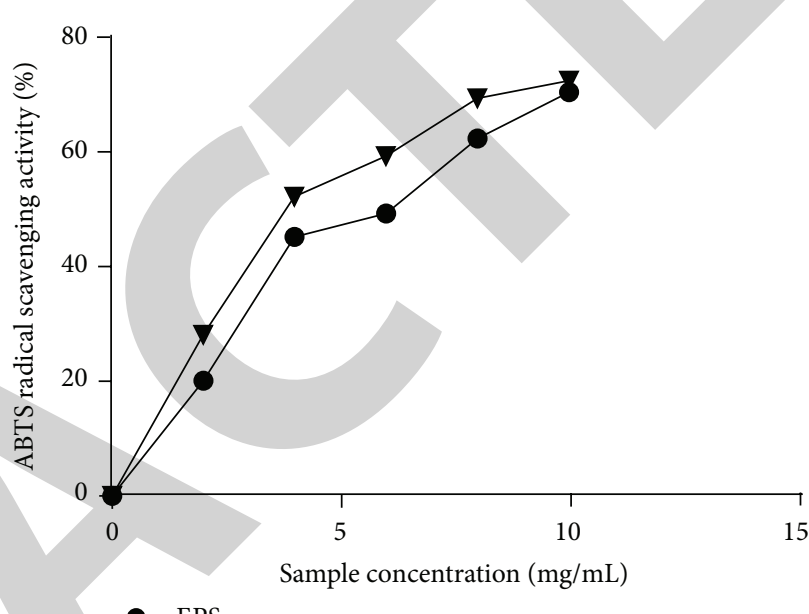

(d)

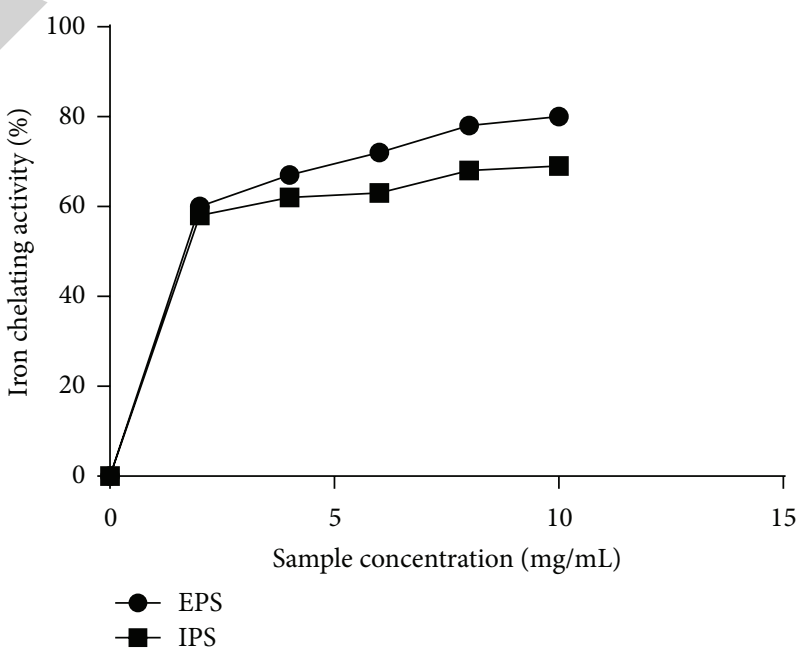

(f)

FIGURE 1: (a) Wild fruit body of C. gracilis on Hymenoptera insect. (b) Four-day-old mycelium on potato dextrose agar (PDA) medium. (c) DPPH scavenging activity of EPS and IPS. (d) ABTS radical scavenging activity of EPS and IPS. (e) Reducing power of EPS and IPS. (f) Iron chelating activity of EPS and IPS.

the extracts increased with increasing concentration as shown in the figure. At a concentration of $10.0 \mathrm{mg} / \mathrm{mL}$, the percentage inhibition of EPS and IPS was found to be the same. High concentrations of the EPS and IPS are able to quench the free radicals in the system. The results indicated that the EPS and IPS of C. gracilis possessed significant scavenging power for the ABTS radicals (Figure 1(d)).

The results obtained for reducing power abilities of EPS and IPS in submerged culture of C. gracilis showed that both types of polysaccharides possessed the high reducing 
TABLE 4: Results obtained for orthogonal design.

\begin{tabular}{|c|c|c|c|c|c|c|}
\hline Experimental group & Temperature $\left({ }^{\circ} \mathrm{C}\right)$ & $\mathrm{pH}$ & Rotation speed/min & Culture time/d & EPS (mg/L) & IPS (mg/L) \\
\hline 1 & 1 & 1 & 1 & 1 & $316.83 \pm 2.35$ & $276.83 \pm 1.65$ \\
\hline 2 & 1 & 2 & 2 & 2 & $465.17 \pm 12.16$ & $315.10 \pm 12.16$ \\
\hline 3 & 1 & 3 & 3 & 3 & $384.25 \pm 16.10$ & $324.20 \pm 16.10$ \\
\hline 4 & 2 & 1 & 2 & 3 & $618.49 \pm 34.15$ & $398.19 \pm 34.15$ \\
\hline 5 & 2 & 2 & 3 & 1 & $598.69 \pm 14.10$ & $408.60 \pm 14.10$ \\
\hline 6 & 2 & 3 & 1 & 2 & $648.69 \pm 9.18$ & $441.61 \pm 7.58$ \\
\hline 7 & 3 & 1 & 3 & 2 & $248.11 \pm 44.47$ & $198.20 \pm 14.07$ \\
\hline 8 & 3 & 2 & 1 & 3 & $362.11 \pm 3.75$ & $252.18 \pm 7.75$ \\
\hline 9 & 3 & 3 & 2 & 1 & $206.76 \pm 58.91$ & $176.76 \pm 18.01$ \\
\hline$\overline{K_{1}}$ & 11.26 & 9.28 & 15.26 & 14.89 & & \\
\hline$K_{2}$ & 24.10 & 14.60 & 13.90 & 15.10 & & \\
\hline$K_{3}$ & 11.15 & 9.05 & 14.15 & 14.15 & & \\
\hline$R$ & 12.17 & 4.67 & 0.82 & 2.69 & & \\
\hline$K_{1}{ }^{*}$ & 451.56 & 351.84 & 424.43 & 327.16 & & \\
\hline$K_{2}{ }^{*}$ & 678.59 & 576.19 & 622.09 & 478.59 & & \\
\hline$K_{3}{ }^{*}$ & 302.11 & 342.17 & 362.71 & 444.11 & & \\
\hline$R^{*}$ & 389.38 & 84.08 & 25.38 & 92.18 & & \\
\hline
\end{tabular}

\begin{tabular}{lcc}
\hline $\mathrm{EC}_{50}$ & $\mathrm{EPS}(\mathrm{mg} / \mathrm{mL})$ & $\mathrm{IPS}(\mathrm{mg} / \mathrm{mL})$ \\
\hline DPPH radical scavenging activity & $7.32 \pm 0.09$ & $6.79 \pm 0.04$ \\
ABTS radical scavenging activity & $7.08 \pm 0.32$ & $5.11 \pm 0.22$ \\
Reducing power & $6.96 \pm 0.22$ & $5.33 \pm 0.27$ \\
Iron chelating activity & $1.64 \pm 0.41$ & $1.49 \pm 0.21$ \\
\hline
\end{tabular}

Results obtained under present investigations showed that Cordyceps gracilis is a medicinal fungus and it contained both EPS and IPS in appreciable amount. In vitro evaluation of antioxidant activities of EPS and IPS showed significant higher antioxidant activities. However, submerged cultivation of this fungus required several factors for the production of EPS and IPS. Factors such as temperature, rotation speed, $\mathrm{pH}$, incubation time, carbon, nitrogen, and carbon to nitrogen ratio showed significant effect on the production of EPS and IPS. Due to significantly higher DPPH radical scavenging activity, ABTS radical scavenging activity, reducing power, and iron chelating abilities, this fungus is useful for its pharmaceutical applications. Present findings will open the scope for its large-scale industrial fermentations for commercial uses like other commercially explored Cordyceps species.

\section{Conflict of Interests}

The authors declare that there is no conflict of interests regarding the publication of this paper.

\section{Acknowledgment}

Sapan Kumar Sharma wishes to thank Science and Engineering Board, Department of Science and Technology, New Delhi, for research grant under Young Scientist Scheme (SB/FT/LS-04/2013) for carrying out present studies.

\section{References}

[1] Y. Kobayasi, "Keys to the taxa of the genera Cordyceps and Torrubiella," Transactions of the Mycological Society of Japan, vol. 23, pp. 329-364, 1982. 
[2] Ø. Stensrud, N. L. Hywel-Jones, and T. Schumacher, "Towards a phylogenetic classification of Cordyceps: ITS nrDNA sequence data confirm divergent lineages and paraphyly," Mycological Research, vol. 109, no. 1, pp. 41-56, 2005.

[3] P. M. Kirk, P. Cannon, J. C. David, and J. A. Stalpers, Ainsworth and Bisby's Dictionary of the Fungi, CAB International, Wallingford, UK, 10th edition, 2008.

[4] D.-B. Ji, J. Ye, C.-L. Li, Y.-H. Wang, J. Zhao, and S.-Q. Cai, "Antiaging effect of Cordyceps sinensis extract," Phytotherapy Research, vol. 23, no. 1, pp. 116-122, 2009.

[5] T. Kiho, A. Yamane, J. Hui, S. Usui, and S. Ukai, "Polysaccharides in fungi. XXXVI.1 Hypoglycemic activity of a polysaccharide (CS-F30) from the cultural mycelium of Cordyceps sinensis and its effect on glucose metabolism in mouse liver," Biological and Pharmaceutical Bulletin, vol. 19, no. 2, pp. 294-296, 1996.

[6] Y.-J. Chen, M.-S. Shiao, S.-S. Lee, and S.-Y. Wang, "Effect of Cordyceps sinensis on the proliferation and differentiation of human leukemic U937 cells," Life Sciences, vol. 60, no. 25, pp. 2349-2359, 1997.

[7] Y. B. Ji, "Pharmacological actions and applications of anticancer traditional Chinese medicines (150. Cordycepssinensis (Berk) Sacc)," Heilongjiang Ke-Xue-Ji-Shu Chu-Ban-She, pp. 494-501, 1999 (Chinese).

[8] T. Mizuno, "Medicinal effects and utilization of Cordyceps (Fr.) link (Ascomycetes) and Isaria Fr. (Mitosporic fungi) Chinese caterpillar fungi, 'Tochukaso' (Review),' International Journal of Medicinal Mushrooms, vol. 1, no. 3, pp. 251-261, 1999.

[9] S. W. Kim, H. J. Hwang, C. P. Xu, Y. S. Na, S. K. Song, and J. W. Yun, "Influence of nutritional conditions on the mycelial growth and exopolysaccharide production in Paecilomyces sinclairii," Letters in Applied Microbiology, vol. 34, no. 6, pp. 389-393, 2002.

[10] C. S. Zhao, W. T. Yin, J. Y. Wang et al., "CordyMax Cs-4 improves glucose metabolism and increases insulin sensitivity in normal rats," Journal of Alternative and Complementary Medicine, vol. 8, no. 3, pp. 309-314, 2002.

[11] J. E. Smith, N. J. Rowan, and R. Sullivan, "Medicinal mushrooms: a rapidly developing area of biotechnology for cancer therapy and other bioactivities," Biotechnology Letters, vol. 24, no. 22, pp. 1839-1845, 2002.

[12] X. Ma, D. K. Qiu, J. Xu, J. Q. Li, and M. D. Zeng, "Effect of Cordyceps polysaccharide-liposome on transforming growth factor b-1 in the experimental liver fibrotic rats," Chinese Journal of Gastroenterology, vol. 4, pp. 205-206, 1999.

[13] C. Lu, Preventive activity of Cordyceps polysaccharides on nonalcoholic steatohepatitis and their partial mechanismsof action [M.S. thesis], Anhui Medical University, Anhui, China, 2005.

[14] E. J. Buenz, B. A. Bauer, T. W. Osmundson, and T. J. Motley, “The traditional Chinese medicine Cordyceps sinensis and its effects on apoptotic homeostasis," Journal of Ethnopharmacology, vol. 96, no. 1-2, pp. 19-29, 2005.

[15] F.-H. Li, P. Liu, W.-G. Xiong, and G.-F. Xu, "Effects of Corydyceps polysaccharide on liver fibrosis induced by DMN in rats," China Journal of Chinese Materia Medica, vol. 31, no. 23, pp. 1968-1971, 2006.

[16] J. Chen, W. Zhang, T. Lu, J. Li, Y. Zheng, and L. Kong, "Morphological and genetic characterization of a cultivated Cordyceps sinensis fungus and its polysaccharide component possessing antioxidant property in H22 tumor-bearing mice," Life Sciences, vol. 78, no. 23, pp. 2742-2748, 2006.

[17] J. L. Liu and Y. Fei, "Enhancement of Cordyceps taii polysaccharide and Cordyceps pruinosa polysaccharide on cellular immune function in vitro," Journal of Immunology, vol. 17, no. 3, pp. 189191, 2001.

[18] J. Yang, W. Zhang, P. Shi, J. Chen, X. Han, and Y. Wang, "Effects of exopolysaccharide fraction (EPSF) from a cultivated Cordyceps sinensis fungus on c-Myc, c-Fos, and VEGF expression in B16 melanoma-bearing mice," Pathology Research and Practice, vol. 201, no. 11, pp. 745-750, 2005.

[19] H. O. Kim and J. W. Yun, "A comparative study on the production of exopolysaccharides between two entomopathogenic fungi Cordyceps militaris and Cordyceps sinensis in submerged mycelial cultures," Journal of Applied Microbiology, vol. 99, no. 4, pp. 728-738, 2005.

[20] C. Hobbs, Medicinal Mushrooms: An Exploration of Tradition, Healing, and Culture, Botanica Press, Santa Cruz, Calif, USA, 1995.

[21] R. Yu, L. Song, Y. Zhao et al., "Isolation and biological properties of polysaccharide CPS-1 from cultured Cordyceps militaris," Fitoterapia, vol. 75, no. 5, pp. 465-472, 2004.

[22] T.-H. Hsu, L.-H. Shiao, C. Hsieh, and D.-M. Chang, "A comparison of the chemical composition and bioactive ingredients of the Chinese medicinal mushroom Dong Chong Xia Cao, its counterfeit and mimic, and fermented mycelium of Cordyceps sinensis," Food Chemistry, vol. 78, no. 4, pp. 463-469, 2002.

[23] M.-F. Moradali, H. Mostafavi, S. Ghods, and G.-A. Hedjaroude, "Immunomodulating and anticancer agents in the realm of macromycetes fungi (macrofungi)," International Immunopharmacology, vol. 7, no. 6, pp. 701-724, 2007.

[24] J.-H. Koh, J.-M. Kim, U.-J. Chang, and H.-J. Suh, "Hypocholesterolemic effect of hot-water extract from mycelia of Cordyceps sinensis," Biological and Pharmaceutical Bulletin, vol. 26, no. 1, pp. 84-87, 2003.

[25] S. P. Li, K. J. Zhao, Z. N. Ji et al., "A polysaccharide isolated from Cordyceps sinensis, a traditional Chinese medicine, protects PC12 cells against hydrogen peroxide-induced injury," Life Sciences, vol. 73, no. 19, pp. 2503-2513, 2003.

[26] B. M. Huang, S. Y. Ju, C. S. Wu, W. J. Chuang, C. C. Sheu, and S. F. Leu, "Cordyceps sinensis and its fractions stimulate MA-10 mouse leydig tumor cell steroidogenesis," Journal of Andrology, vol. 22, no. 5, pp. 831-837, 2001.

[27] F. Meng, X. Liu, L. Jia, Z. Song, P. Deng, and K. Fan, “Optimization for the production of exopolysaccharides from Morchella esculenta SO-02 in submerged culture and its antioxidant activities in vitro," Carbohydrate Polymers, vol. 79, no. 3, pp. 700-704, 2010.

[28] X.-X. Lin, Q.-M. Xie, W.-H. Shen, and Y. Chen, "Effects of fermented Cordyceps powder on pulmonary function in sensitized guinea pigs and airway inflammation in sensitized rats," Zhongguo Zhong Yao Za Zhi, vol. 26, no. 9, pp. 622-625, 2001.

[29] R. M. Yu, Y. Yin, W. Yang et al., "Structural elucidation and biological activity of a novel polysaccharide by alkaline extraction from cultured Cordyceps militaris," Carbohydrate Polymers, vol. 75, no. 1, pp. 166-171, 2009.

[30] F. Shahidi and P. K. J. P. D. Wanasundara, "Phenolic antioxidants," Critical rReviews in Food Science and Nutrition, vol. 32, no. 1, pp. 67-103, 1992.

[31] N. Abdullah, S. M. Ismail, N. Aminudin, A. S. Shuib, and B. F. Lau, "Evaluation of selected culinary-medicinal mushrooms for antioxidant and ACE inhibitory activities," Evidence-Based Complementary and Alternative Medicine, vol. 2012, Article ID 464238, 12 pages, 2012. 
[32] T. H. Bang, H. Suhara, K. Doi et al., "Wild mushrooms in Nepal: some potential candidates as antioxidant and ACEinhibition sources," Evidence-Based Complementary and Alternative Medicine, vol. 2014, Article ID 195305, 11 pages, 2014.

[33] H.-C. Huang and Y.-C. Liu, "Enhancement of polysaccharide production by optimization of culture conditions in shake flask submerged cultivation of Grifola umbellata," Journal of the Chinese Institute of Chemical Engineers, vol. 39, no. 4, pp. 307311, 2008.

[34] C. P. Pokhrel and S. Ohga, "Submerged culture conditions for mycelial yield and polysaccharides production by Lyophyllum decastes," Food Chemistry, vol. 105, no. 2, pp. 641-646, 2007.

[35] D.-H. Kim, B.-K. Yang, S.-C. Jeong et al., "Production of a hypoglycemic, extracellular polysaccharide from the submerged culture of the mushroom, Phellinus linteus," Biotechnology Letters, vol. 23, no. 7, pp. 513-517, 2001.

[36] M. Papagianni, "Fungal morphology and metabolite production in submerged mycelial processes," Biotechnology Advances, vol. 22, no. 3, pp. 189-259, 2004.

[37] X. U. Qinqin, L. I. U. Zhenhua, S. U. N. Yisheng, D. I. N. G. Zhongjie, L. Ü. Longxian, and L. I. Yongquan, "Optimization for production of intracellular polysaccharide from Cordyceps ophioglossoides L2 in submerged culture and its antioxidant activities in vitro," Chinese Journal of Chemical Engineering, vol. 20, no. 2, pp. 294-301, 2012.

[38] Q. Xu, L. Lü, S. Chen, G. Zheng, J. Zheng, and Y. Li, "Isolation of Cordyceps ophioglossoides L2 from fruit body and optimization of fermentation conditions for its mycelial growth," Chinese Journal of Chemical Engineering, vol. 17, no. 2, pp. 278-285, 2009.

[39] Q.-H. Fang and J.-J. Zhong, "Submerged fermentation of higher fungus Ganoderma lucidum for production of valuable bioactive metabolites-ganoderic acid and polysaccharide," Biochemical Engineering Journal, vol. 10, no. 1, pp. 61-65, 2002.

[40] M.-Y. Lung and Y.-C. Chang, "In vitro antioxidant properties of polysaccharides from Armillaria mellea in batch fermentation," African Journal of Biotechnology, vol. 10, no. 36, pp. 7048-7057, 2011.

[41] N. S. Atri, S. K. Sharma, R. Joshi, and A. Gulati, "Nutritional and neutraceutical composition of five wild culinarymedicinal species of genus Pleurotus (Higher Basidiomycetes) from Northwest India," International Journal of Medicinal Mushrooms, vol. 15, no. 1, pp. 49-56, 2013.

[42] E. Vamanu, "Biological activities of the polysaccharides produced in submerged culture of two edible Pleurotus ostreatus mushrooms," Journal of Biomedicine and Biotechnology, vol. 2012, Article ID 565974, 8 pages, 2012.

[43] P. Li, L. Huo, W. Su et al., "Free radical-scavenging capacity, antioxidant activity and phenolic content of Pouzolzia zeylanica," Journal of the Serbian Chemical Society, vol. 76, no. 5, pp. 709-717, 2011.

[44] C. M. Papuc, M. Crivineanu, G. Goran, V. Nicorescu, and N. Durdun, "Free radicals scavenging and antioxidant activity of European mistletoe (Viscum album) and European birthwort (Aristolochia clematitis)," Revista de Chimie, vol. 61, no. 7, pp. 619-622, 2010.

[45] V. O. Oyetayo, C.-H. Dong, Y.-J. Yao, and T. Jackson, "Antioxidant and antimicrobial properties of aqueous extract from Dictyophora indusiata," The Open Mycology Journal, vol. 3, no. 1, pp. 20-26, 2009.

[46] C. Hsieh, M.-J. Tsai, T.-H. Hsu, D.-M. Chang, and C.-T. Lo, "Medium optimization for polysaccharide production of
Cordyceps sinensis," Applied Biochemistry and Biotechnology, vol. 120, no. 2, pp. 145-157, 2005.

[47] C.-H. Dong and Y.-J. Yao, "Nutritional requirements of mycelial growth of Cordyceps sinensis in submerged culture," Journal of Applied Microbiology, vol. 99, no. 3, pp. 483-492, 2005.

[48] Y. S. Kim, K. S. Park, H. S. Park, and S. W. Kim, "Compositional sugar analysis of antitumor polysaccharides by high performance liquid chromatography and gas chromatography," Archives of Pharmacal Research, vol. 17, no. 5, pp. 337-342, 1994.

[49] Y. Kwan-Won, H.-J. Suh, S. H. Bae, C. S. Lee, S. H. Kim, and C.-S. Yoon, "Chemical properties and physiological activities of stromata of Cordyceps militaris," Journal of Microbiology and Biotechnology, vol. 11, no. 2, pp. 266-274, 2001.

[50] H. Yan, D. Zhu, D. Xu, J. Wu, and X. Bian, “A study on Cordyceps militaris polysaccharide purification, composition and activity analysis," African Journal of Biotechnology, vol. 7, no. 22, pp. 4004-4009, 2008.

[51] Y.-X. Gu, Y.-W. Song, L.-Q. Fan, and Q.-S. Yuan, "Antioxidant activity of natural and cultured Cordyceps sp.", Zhongguo Zhong Yao Za Zhi, vol. 32, no. 11, pp. 1028-1031, 2007.

[52] X. Yuan, H. Sun, Y. Liu et al., "Anti-cancer activity comparisons of aqueous extracts from Inonotus obliquus, Cordyceps militaris and Uncaria tomentosain vitro and in vivo," Journal of Pharmacognosy and Phytochemistry, vol. 2, no. 6, pp. 19-25, 2014.

[53] P. H. Leung, S. Zhao, K. P. Ho, and J. Y. Wu, "Chemical properties and antioxidant activity of exopolysaccharides from mycelial culture of Cordyceps sinensis fungus Cs-HK1," Food Chemistry, vol. 114, no. 4, pp. 1251-1256, 2009.

[54] C.-H. Dong, T. Yang, and T. Lian, "A comparative study of the antimicrobial, antioxidant, and cytotoxic activities of methanol extracts from fruit bodies and fermented mycelia of caterpillar medicinal mushroom Cordyceps militaris (Ascomycetes)," International Journal of Medicinal Mushrooms, vol. 16, no. 5, pp. 485495, 2014.

[55] J. A. Vinson, Y. Hao, X. Su, and L. Zubik, "Phenol antioxidant quantity and quality in foods: vegetables," Journal of Agricultural and Food Chemistry, vol. 46, no. 9, pp. 3630-3634, 1998.

[56] S. Enayat and S. Banerjee, "Comparative antioxidant activity of extracts from leaves, bark and catkins of Salix aegyptiaca sp." Food Chemistry, vol. 116, no. 1, pp. 23-28, 2009. 